\title{
Treatment Pattern and Awareness of Migraine in Eastern Provinces, Saudi Arabia: A Descriptive Cross Sectional Study
}

\author{
Ayaz Ahmad, Mohammad Daud Ali*, Yousif Amin Mohamed Hassan, Reemah Shabak Al Dhefairy, Samar Thamer Al Saad, Rahmah Jassim \\ Al Khalifa \\ Department of Pharmacy, Mohammed Al-Mana College for Medical Sciences, Abdulrazaq Bin Hammam Street, As Safa, Dammam, 34222, SAUDI ARABIA.
}

\begin{abstract}
Objectives: This study aimed is to identify treatment pattern and awareness of migraine in Eastern provinces of Saudi Arabia. Methods: The survey questionnaire used to assess the awareness and treatment pattern of migraine was adopted from previous study. The questionnaire contains three sections. The first section contained of items related to demographic information of the participants. The second section contains to assess the knowledge of participants towards migraine. The third part of questionnaire contains about different types of therapy used in treatment of migraine. Results: Overall awareness of migraine among participants from Eastern Provinces of Saudi Arabia is $81.81 \% .98 .60 \%$ participants have heard about the migraine. Nearly $40 \%$ of participants are suffering from migraine and main cause of it is stress and tension. Panadol and Brufen drugs were used by almost migraine patient. Although few migraine patient were also used Rapidus. Conclusion: There is higher occurrence of migraine in women
\end{abstract}

than in men by ratio of 12:1. Despite of having good knowledge of migraine $(81.81 \%)$, only $39.16 \%$ participants know about the causes of migraine and only $26.80 \%$ of participants know about the preventive measures of migraine. Thus educational and preventive health campaigns are needed all over the Saudi Kingdom.

Key words: Knowledge, Practice, Migraine, Prevention, Treatment, Kingdom of Saudi Arabia.

Correspondence

Dr. Mohammad Daud Ali,

Department of Pharmacy, Mohammed Al-Mana College for Medical Sciences, Abdulrazaq Bin Hammam Street, As Safa, Dammam, 34222, SAUDI ARABIA.

Phone no: +966537018749

Email: dali.niper@gmail.com

DOI: 10.5530/ijpi.2020.2.41

\section{INTRODUCTION}

A migraine is pulsating or throbbing a disorder characterized by recurrent moderate to severe pain. ${ }^{1}$ It produces one sided intense pain of head. ${ }^{2}$ Migraine is the fifth utmost important cause for women among all diseases worldwide causing disability and for men, it is one of the top twenty diseases. ${ }^{3}$ After tension headache, the $2^{\text {nd }}$ general kind of primary headaches are the migraine headaches. Primary headache is the headache that are not the result of another medical condition. ${ }^{4}$ It is considered as persistent unilateral headache united with neurologic and gastrointestinal disturbances that can severely influence the quality of living and daily activities. ${ }^{5}$ Migraine can further causes physical and psychiatric problem. ${ }^{6}$ Worldwide, near about $15 \%$ of population are suffered from migraines. ${ }^{1}$ According to global burden of disease (GBD) survey 2016, leading causes of disability is migraine. ${ }^{7}$ Diagnosis of migraine is not as easy as it depends on multiple conditions and may be inappropriately diagnosed. ${ }^{8}$ A study revealed that around $33 \%$ of migraine patients were appropriately diagnosed which result in distressing the quality of life. ${ }^{9}$ The primary step for appropriate and efficient therapy of migraine is correct diagnosis, eliminating alternative causes, educating the patient and finding better treatment for management of pain. ${ }^{10}$ The pharmacologic therapy has two options that can be taken separately or together for patients with severe migraine including acute or preventive measures. ${ }^{11}$

The preventive treatment can be applied for reducing the penetrating, duration and severity of migraine attacks. ${ }^{12}$ Enlightening the knowledge and treatment pattern among adult population can outcome in prevention of migraine episodes and its effect on quality of life. This study aimed at treatment Pattern and Awareness of Migraine in Eastern provinces of Saudi Arabia.

\section{MATERIALS AND METHODS}

\section{Study design}

A cross sectional questionnaire based study was conducted based on a self-administered questionnaire, study was conducted at Eastern province, Saudi Arabia for a period of 3 months from February to April 2018. More than 18 years of age will be included in the study and either gender can participate in study. Incomplete information given by participants will not be included in the study.

\section{Sampling and sample size}

The sample size was estimated by using Krejcie and Morgan's sample size calculator. ${ }^{13} \mathrm{~A}$ suitability sampling technique was used to recruit a sample of 858 participants from residents of Eastern province, Saudi Arabia.

\section{Survey instrument}

The survey questionnaire used to assess the awareness and treatment pattern of migraine was adopted from previous study. ${ }^{14}$

The questionnaire contains three sections. The first section contained of items related to demographic information of the participants. The second section contains to assess the knowledge of participants towards migraine. The third part of questionnaire contains about different types of therapy used in treatment of migraine.

\section{Ethical approval}

Before the conduction of the study, the study protocol was reviewed and approved by the scientific research Unit Mohammed Al-Mana College for Medical Sciences (SR/RP/09B), Saudi Arabia. Declaration of Helsinki guidelines is followed for the full compliance of study. ${ }^{15}$ 


\section{Data analysis}

Evaluation of data was done by using the Statistical Package for the Social Sciences (SPSS, V. 22). Demonstration of demographic characteristics were done by descriptive statistics. Categorical variables were presented in terms of frequency and percentages. Chi-square test were used for the calculation of association and differences. A $p$ value $<0.05$ was considered statistically significant.

\section{RESULTS}

The questionnaire were distributed to 950 subjects and among them 852 given the response with an overall response rate of $89 \%$. All participants surveyed were Saudis. There were $767(89.39 \%, p<0.05)$ Female and $91(10.60 \%, p<0.05)$ Male. Study participants were within the age group from 20 to 50 years. As shown in Table 1, $1.28 \%$ of the subjects were from primary school, $24.4 \%$ from Secondary school, $5 \%$ from Intermediate followed by Graduate (63.63\%), Postgraduate students (4.31\%) with $P$-value $<0.05$. The maximum percentage of participants were unemployed $(49.30 \%, p<0.05)$ while the least participants were Student $(21.91 \%, p<0.05)$. Among all the participants, maximum were from urban residents (90.64\%). $32.98 \%$ participants were the mother of less than three children and $40.90 \%$ participants were the mother of more than three children with $P$-value $<0.05$.

Assessment of knowledge among participants toward migraine were shown in Table 2. It was found that $98.60 \%(p<0.05)$ candidates heard about the disease called migraine while $1.3 \%(p<0.05)$ candidates have not heard about the term "migraine."

Reason of migraine has been shown in Figure 1. It was found that the major cause or trigger of migraine was stress or tension (26.92\%).

The percentage of various therapies used by participants has been shown in Figure 2. It was found that majority of participants have used medication $(64.68 \%)$ while very few participants have used accupuncture $(3.10 \%)$.

\section{DISCUSSION}

Migraine is a common neurological disorder affecting in Eastern region, Saudi population. This was the first study about treatment pattern and awareness of migraine in Eastern provinces, Saudi Arabia. The knowledge of migraine in Eastern province of Saudi Arabia was found to be higher than the knowledge reported in different studies. A general knowledge and attitude of migraine has been shown in Table 2. $81.81 \%(p<0.05)$ candidates were having knowledge about the migraine while $18.18 \%(p$ $<0.05)$ candidates were having no idea about the migraine. For example, headache was reported in $33 \%$ of individuals studied in Taif, $70 \%$ in India and $43.2 \%$ in all over Kingdom of Saudi Arabia (KSA). ${ }^{11,14,16}$

The third question was asked to find whether they know about the difference of normal headache and migraine. There were $75.05 \%$ $(p<0.05)$ candidates who knew the difference between headache and migraine; and $24.94 \%(p<0.05)$ candidates too who did not know the difference between headache and migraine. The knowledge about the differences between normal headache and migraine headache in Eastern province of Saudi Arabia was also found to be higher than the knowledge reported in other studies. For instance, only $56 \%$ of individuals was aware about differences between normal headache and migraine headache studied in India 2017. ${ }^{14}$

The fourth question was asked to find out the family history of migraine. $56.64 \%(p<0.05)$ candidates were those who are having family history of migraine and $43.35 \%(p<0.05)$ candidates were not having family history of migraine. This is in agreement with previous literature studies that indicated high prevalence of positive family history among migraine patients, ${ }^{16,17}$ but also it is contrast to previous study where only $18 \%$ candidates were having family history of migraine. ${ }^{14}$

Out of those $56.64 \%$ of candidates who were having family history of migraine, there were only $46.29 \%$ of candidates who are suffering from migraine and $53.70 \%$ of candidates were also those who are not suffering from migraine. From it we conclude that, it is not mandatory that if your parents have migraine, you will also suffer from migraine but then chances of developing migraine in children increases; and it is also not like that if you do not have family history of migraine, you cannot develop migraine but if you have a family history of migraine, there are more chances that you can also suffer from migraine.

The fifth question was asked to find out awareness of causes of migraine among the population. $39.16 \%(p<0.05)$ candidates were those who knew about the causes of migraine and $60.83 \%(p<0.05)$ candidates were those who did not aware about the causes of migraine. Similar result were shown by previous studies where $36 \%$ candidates were those who knew about the causes of migraine. ${ }^{14}$ While in other study, $62 \%$ was aware about the causes of migraine. ${ }^{18}$

The sixth question asked among population was about the awareness of the signs and symptoms of migraine there were $56.87 \%(p<0.05)$ candidates who were familiar with the signs and symptoms of migraine,

\section{Table 1: Socio-Demographic Characteristics of Participants.}

\begin{tabular}{|c|c|c|}
\hline $\begin{array}{l}\text { Socio-demographic } \\
\text { Characteristics }\end{array}$ & N (\%) & *P-Value \\
\hline Age ( Years ) & & $p<0.05$ \\
\hline $20-30$ & $447(52.09)$ & \\
\hline $30-40$ & $287(33.44)$ & \\
\hline $40-50$ & $124(14.45)$ & \\
\hline Gender & & $p<0.05$ \\
\hline Female & $767(89.39)$ & \\
\hline Male & $91(10.60)$ & \\
\hline Number of children. & & \\
\hline No children & $324(37.76)$ & $p<0.05$ \\
\hline Less than 3 children & $283(32.98)$ & \\
\hline 3 children or more & $251(40.90)$ & \\
\hline Education level & & $p<0.05$ \\
\hline Primary & $11(1.28)$ & \\
\hline Secondary & $221(24.4)$ & \\
\hline Intermediate & $43(5.01)$ & \\
\hline Graduate & $546(63.63)$ & \\
\hline Postgraduate & $37(4.31)$ & \\
\hline Employment status & & $p<0.05$ \\
\hline Employed & $247(28.78)$ & \\
\hline Student & $188(21.91)$ & \\
\hline Unemployed & $423(49.30)$ & \\
\hline \multicolumn{3}{|l|}{ Residence } \\
\hline & & 0.36 \\
\hline Rural & $55(6.41)$ & \\
\hline Urban & 803(93.58) & \\
\hline
\end{tabular}

${ }^{\star} P$-value is considered statistically significant when it is $p<0.05$. 
whereas $43.12 \%(p<0.05)$ candidates were those also who did not know about the signs and symptoms of migraine. This result resemble with previous literature studies that indicated 58\% candidates who were familiar with the signs and symptoms of migraine, ${ }^{14}$ but in contrast to previous study it was found that $74 \%$ participants were aware about the signs and symptoms of migraine. ${ }^{18}$

One question was asked that "what is the most common symptom of migraine they experience." From the result, more than $49.38 \%$ of candidates experience throbbing or pulsating pain in the head as the major symptom during migraine attack.

The seventh question asked from the population was about awareness of preventive measures of migraine. From the result, it was found that only $26.80 \%(p<0.05)$ candidates were completely aware about the preventive measures of migraine whereas $73.19 \%(p<0.05)$ candidates were those who were not having any awareness about the preventive measures of migraine. In agreement with our results, Kaur et al. 2017, reported in their study that $19 \%$ participants were fully aware about the preventive measures of migraine while in another study awareness about the preventive measures of migraine were reported $49.8 \% .^{11}$

The eighth question was about the awareness of the treatment of migraine, asked from population. $33.10 \%(p<0.05)$ candidates were those who were aware about the treatment of migraine, whereas $66.89 \%$ $(p<0.05)$ candidates were those who did not know about the treatment of migraine. This finding exist between the two previous studies done by Safila Naveed et al. 2014 and Kaur et al. 2017 and the result were reported $46 \%$ and $23 \%$ respectively. As per our study $19.5 \%$ of migraine patients have used mainly paracetamol and Ibuprofen while $52 \%$ migraine patients have used paracetamol, ibuprofen and diclofenac. While in another study it has been reported that Sumatriptan is the most commonly used medication by the patients for treatment of their migraine. ${ }^{14}$

The final question asked from the population was regarding the incidence of migraine. From the result, it was found that there were $39.86 \%$ $(p<0.05)$ candidates who are suffering from migraine while $60.13 \%$ $(p<0.05)$ candidates are not suffering from migraine. The occurrence of migraine in males was found to be $7.8 \%$ while in females, it was found to be $92.2 \%$. Therefore, there is higher occurrence of migraine in women than in men by ratio of 12:1. This result was coincided with previous result where frequency of migraine in women was found to be more as compared to male. ${ }^{16}$

Then, one more question was also asked from the migraine sufferers, according to them what are the reason of their migraine. According to the analysis of their responses, it was found that the major cause or trigger of their migraine was stress or tension. The percentage of several causes which leads to migraine have been shown in Figure 1. Stress and tension were also reported as major cause for migraine in another study. ${ }^{14,16,18}$

The migraine sufferers, who were using remedies for the treatment of their migraine, the data about those remedies, were also collected. According to the analysis of data obtained from migraine patients, medication is found to be the most used treatment for their migraine (Figure 2) and apart from the medication, Physiotherapy has also found to be effective

Table 2: Knowledge and attitude of participants about use of medication during migraine.

\begin{tabular}{ccccc}
\hline S.No. & Statement & Yes, $\mathbf{N}(\%)$ & No, N (\%) & $* \boldsymbol{P}$-Value \\
\hline 1 & Have you ever heard about the disease called migraine? & $846(98.60)$ & $12(1.3)$ & p $<0.05$ \\
2 & Do you know about migraine? & $702(81.81)$ & $156(18.18)$ & $p<0.05$ \\
3 & Do you know the difference between the headache and & $644(75.05)$ & $214(24.94)$ & $p<0.05$ \\
& migraine? & & \\
4 & Dose any member of your family suffer from migraine? & $486(56.64)$ & $372(43.35)$ & $p<0.05$ \\
5 & Do you know about the causes of migraine? & $336(39.16)$ & $522(60.83)$ & $p<0.05$ \\
6 & Do you know about the signs and symptoms of migraine? & $488(56.87)$ & $370(43.12)$ & $p<0.05$ \\
7 & Do you know about the preventive measures of migraine? & $230(26.80)$ & $628(73.19)$ & $p<0.05$ \\
8 & Do you know about the treatment that use in migraine? & $284(33.10)$ & $574(66.89)$ & $p<0.05$ \\
9 & Do you have a migraine headache? & $342(39.86)$ & $516(60.13)$ & $p<0.05$ \\
\hline
\end{tabular}

${ }^{\star} P$-value is considered statistically significant when it is $p<0.05$.

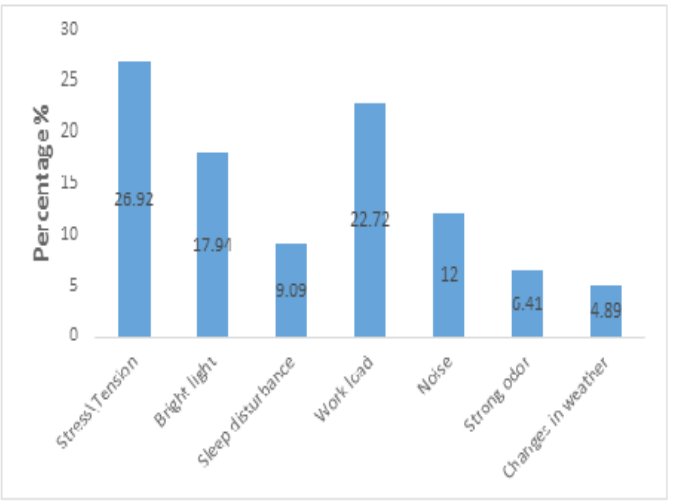

Figure 1: Percentage of various causes of migraine from the migraine sufferers.

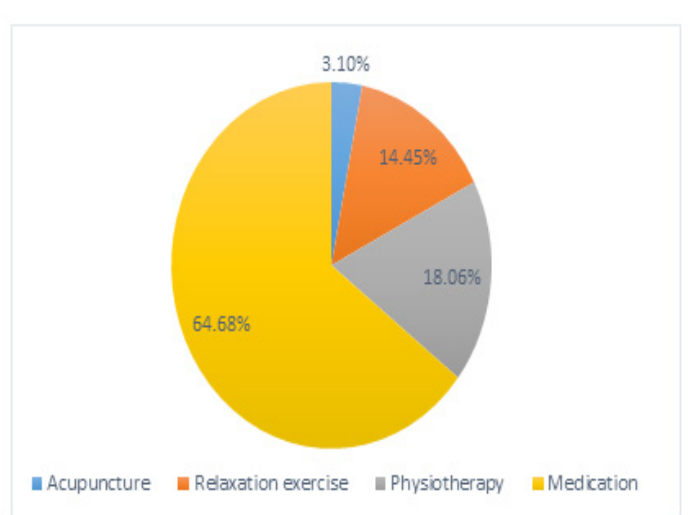

Figure 2: Various therapies used for migraine. 
in treatment. But in few study it has been shown that physiotherapy was major remedies for the treatment of migraine. ${ }^{14}$

\section{CONCLUSION}

It has been observed from this study that the overall awareness of migraine among participants from Eastern Provinces of Saudi Arabia is 81.81\%. 98.60\% participants have heard about the migraine. Nearly $40 \%$ of participants are suffering from migraine and main cause of it is stress and tension. There is higher occurrence of migraine in women than in men by ratio of 12:1. Medication is found to be the most used treatment for their migraine followed by Physiotherapy.

It was found through this study that almost all migraine patient were using mainly paracetamol $500 \mathrm{mg}$ tablet ibuprofen $400 \mathrm{mg}$ tablet and few migraine patient were also using diclofenac $50 \mathrm{mg}$ tablet.

Despite of having good knowledge of migraine (81.81\%), only $39.16 \%$ participants know about the causes of migraine and only $26.80 \%$ of participants know about the preventive measures of migraine. Therefore proper knowledge, positive attitude and practice skills towards migraine are essential for maintain a better quality of life among migraine patients. Thus it is important for the health authorities to launch educational and preventive health campaigns all over the Saudi Kingdom.

\section{ACKNOWLEDGEMENT}

All the authors would like to express thanks to all the respondents who participated in the study.

\section{CONFLICT OF INTEREST}

The authors declare that there are no conflicts of interest.

\section{ABBREVIATIONS}

GBD: Global Burden of Disease; KSA: Kingdom of Saudi Arabia.

\section{REFERENCES}

1. Vos T, Flaxman AD, Naghavi M, Lozano R, Michaud C, Ezzati M, et al. Years lived with disability (YLDs) for 1160 sequelae of 289 diseases and injuries 1990-2010: A systematic analysis for the Global Burden of Disease Study 2010. Lancet
2012;380(9859):2163-96.

2. Naveed S, Hameed A, Sharif N. Awareness and prevalence of migraine, survey based study in Karachi. Int J Biol Sci Appl. 2014;1(4):157-61.

3. Cady RK, Farmer K. Acute and preventative treatment of episodic migraine. Headache and Migraine Biology and Management. $1^{\text {st }}$ ed. USA: Academic Press. 2015;69.

4. University of Maryland Medical Center. Migraine Headaches. 2016. Available from: http://www.umm.edu/health/medical/reports/articles/migraine-headaches. [Last cited on 2017 Jun 12].

5. Hurney C, Faulkner D. Migraine headaches. Pharmacology for Technicians. India: New Age International Publishers. 2005;133-4.

6. Migraine Research Foundation. Migraine Facts. 2016. Available from: https:// www.migraineresearchfoundation.org/about-migraine/ migraine-facts. [Last cited on 2017 Jun 12].

7. GBD 2016 Disease and Injury Incidence and Prevalence, Collaborators. Global, regional and national incidence, prevalence and years lived with disability for 328 diseases and injuries for 195 countries, 1990-2016: A systematic analysis for the Global Burden of Disease Study 2016. Lancet. 2017;390(10100):1211-59.

8. Lipton RB, Manack AA, Buse DC, et al. A comparison of the chronic migraine epidemiology and outcomes (CaMEO) Study. American Migraine Prevalence and Prevention (AMPP) study. Headache. 2016;56(8):1280-9.

9. Wu J, Noxon V, Lu ZK. Patterns of use and health expenses associated with triptans among adults with migraines. The Clinical Journal of Pain. 2015;31(8):6739 .

10. Silberstein SD. Preventive migraine treatment. Lifelong Learning in Neurology. 2015;21(4):973-89.

11. Alkhudhairi OS, Alghthy AM, HindiWS, Alqassemi SI. Assessment of knowledge and attitude and practice towards migraine prevention and treatment among general population in Saudi Arabia. Egyptian J Hosp Med. 2018;73(4):6531-4.

12. Huang TC, Lai TH. Medical treatment guidelines for preventive treatment of migraine. Acta Neurologica Taiwanica. 2017;26(1):33-53.

13. Krejcie RV, Morgan DW. Determining sample size for research activities. Educ Psychol Measur. 1970;30(3):607-10.

14. Amandeep K, Harmanpreet S, Suksham G, Jasjeet KN, Yash PS, Avneet K. Trend of use of different antimigraine medications and awareness of migraine, survey based study in Jalandhar. Asian J Pharm Clin Res. 2017;10(16):32.

15. World Medical Association. Declaration of Helsinki: Ethical principles for medical research involving human subjects. JAMA. 2013;310(20):2191-4.

16. Almalki ZA, Alzhrani MA, Altowairqi AT, Aljawi YA, Fallatah SA, Assaedi LM, et al. Prevalence of Migraine Headache in Taif City, Saudi Arabia. J Clin Med Res. 2018;10(2):125-33.

17. WHO The World Health Report 2001: Mental Health, New Understanding New Hope. World Health Organization Geneva, Swizerland. 2001. (Http:/Mww.Who. Int/Whr/2001/ Main/En/ Overview/Outline. Htm.) [Last cited on Aug. 2015].

18. Naveed S, Hameed A, Sharif N. Awareness and prevalence of migraine, survey based study in Karachi. Int J Biol Sci Appl. 2014;1(4):157-61.

Article History: Submission Date : 31-01-2020; Revised Date : 18-02-2020; Acceptance Date : 14-03-2020.

Cite this article: Ahmad A, Ali MD, Hassan YAM, Dhefairy RSA, Saad STA, Khalifa RJA. Treatment Pattern and Awareness of Migraine in Eastern Provinces,

Saudi Arabia: A Descriptive Cross Sectional Study. Int. J. Pharm. Investigation, 2020;10(2):221-4. 